OPEN ACCESS

Edited by:

Sher Bahadar Khan,

King Abdulaziz University, Saudi Arabia

Reviewed by:

Serge Zhandarov, National Academy of Sciences of

Belarus (MPRI), Belarus

Fabrizio Sarasini,

Sapienza University of Rome, Italy

${ }^{*}$ Correspondence:

Guilherme M. O. Barra g.barra@ufsc.br

Specialty section

This article was submitted to Polymeric and Composite Materials, a section of the journal Frontiers in Materials

Received: 18 April 2019

Accepted: 12 May 2020

Published: 10 June 2020

Citation:

Bertolini MC, Ramoa SDAS, Merlini C,

Barra GMO, Soares BG and Pegoretti A (2020) Hybrid Composites Based on Thermoplastic Polyurethane With a Mixture of Carbon Nanotubes and Carbon Black Modified With Polypyrrole for Electromagnetic Shielding. Front. Mater. 7:174 doi: 10.3389/fmats.2020.00174

\section{Hybrid Composites Based on Thermoplastic Polyurethane With a Mixture of Carbon Nanotubes and Carbon Black Modified With Polypyrrole for Electromagnetic Shielding}

Mayara C. Bertolini ${ }^{1}$, Sillvia D. A. S. Ramoa ${ }^{1}$, Claudia Merlini ${ }^{1,2}$, Guilherme M. O. Barra ${ }^{1 *}$, Bluma G. Soares ${ }^{3}$ and Alessandro Pegoretti ${ }^{4}$

${ }^{1}$ Departamento de Engenharia Mecânica, Universidade Federal de Santa Catarina, Florianópolis, Brazil, ${ }^{2}$ Departamento de Engenharia, Universidade Federal de Santa Catarina, Blumenau, Brazil, ${ }^{3}$ Departamento de Engenharia Metalúrgica e de Materiais, Universidade Federal do Rio de Janeiro, Rio de Janeiro, Brazil, ${ }^{4}$ Department of Industrial Engineering and INSTM Research Unit, University of Trento, Trento, Italy

Hybrid conducting composites comprising thermoplastic polyurethane (TPU) and mixtures of carbon black modified with polypyrrole (CB-PPy) and carbon nanotubes (CNT) were prepared by melt mixing process. The electrical conductivity, rheological properties and electromagnetic shielding effectiveness (EMI SE) of TPU/CB-PPy and TPU/CNT composites were also investigated those results observed for TPU/CB-PPy/CNT hybrid composites. TPU/CNT composites show a very sharp insulator-conductor transition and the electrical percolation threshold was about 1 wt\% of CNT, which was lower than that found for TPU/CB-PPy (7 wt\%). Moreover, EMI SE values of TPU/CNT composites were higher than those for TPU/CB-PPy due to the denser CNT conductive pathway into TPU matrix. In order to achieve the highest electrical conductivity and EMI SE values, mixtures of CB-PPy/CNT were added in the composites in different mass fractions. In fact, the electrical conductivity values increased by combining CB-PPy and CNT, resulting in hybrid composites of TPU/CB-PPy/CNT with higher EMI SE values when compared to TPU/CB-PPy composites. The present study demonstrates the potential use of hybrid polymer composites containing 5 or 8 wt $\%$ of CB-PPy/CNT at specific CB-PPy/CNT ratios with good processabilty and EMI SE values as high as $-20 \mathrm{~dB}$ indicating the potential use of these materials for electromagnetic shielding application in the $\mathrm{X}$-band frequency region.

Keywords: carbon black, polypyrrole, carbon nanotubes, thermoplastic polyurethane, electromagnetic shielding 


\section{INTRODUCTION}

The production of electromagnetic shielding materials has been extensively studied due to the proliferation of electromagnetic interference (EMI) produced by high-performance electronic devices (Håkansson et al., 2007; Ramoa et al., 2013; Kausar, 2016). Metals are the most common materials to prevent EMI; however, these materials have some disadvantages such as high density, low corrosion resistance, high stiffness and processing difficulties (Mahapatra et al., 2008). In this context, the interest in developing electrically conductive polymer composites (CPC) comprising an insulating polymer matrix and a disperse phase of electrically conductive filler has increased because of their low weight, corrosion resistance and ease of processing. Moreover, the electrical properties and electromagnetic shielding effectiveness (EMI SE) of these materials can be modified by adding different amounts of conductive filler into insulating polymer matrix.

Several interesting works concerning the production of EMI shielding polymer composites with improved electrical conductivity and EMI SE values have been reported (Yavuz et al., 2005; Mahapatra et al., 2008; Sudha et al., 2009; Kim et al., 2011; Kaur et al., 2012; Zhang et al., 2012; Al-Saleh et al., 2013; Sharma et al., 2016; Kumar et al., 2017; Kuester et al., 2018; Kumar and Patro, 2018). The most commonly used conductive fillers are carbon fillers, such as carbon nanotubes (CNT) (Mahapatra et al., 2008; Socher et al., 2011; Kaur et al., 2012; Zhang et al., 2012; Al-Saleh et al., 2013; Kumar et al., 2017; Yu et al., 2018), expanded graphite (EG) (Piana and Pionteck, 2013; Kuester et al., 2016), carbon black (CB) (Sumfleth et al., 2009; Chen J. et al., 2013; Burmistrov et al., 2016; Pan et al., 2016; Jeddi and Katbab, 2017; Mondal et al., 2018), graphene (GE) (AlSaleh, 2015; Sharma et al., 2016) and graphene nanoplateles (GnP) (Chu et al., 2012; Al-Saleh, 2016), and intrinsically conducting polymers (ICP), for instance, polypyrrole (PPy) (Yavuz et al., 2005; Taunk et al., 2008) and polyaniline (PAni) (Sudha et al., 2009; Kim et al., 2011; Oyharçabal et al., 2013). Their advantages are good thermal stability, lightweight, ease of processing, and compatibility with polymer matrices. Although significant progress in this field has been achieved, a great effort has been made to produce conductive polymer composites at lower conductive filler concentrations in order to maintain the rheological and mechanical properties of the insulating polymer matrix. There are several strategies available to reduce the electrical percolation threshold in $\mathrm{CPC}$, including the adequate choice of the filler, polymer matrix, manufacturing method and the most suitable processing conditions.

The technique based on dispersion of two or more conductive fillers into an insulating polymer matrix has been used to improve the composite properties. In fact, some works in the open literature demonstrate better EMI SE results when conductive fillers with different geometries are combined into an insulating polymer matrix (Zhang et al., 2012, 2018; Szeluga et al., 2015; Jang et al., 2016; Kumar et al., 2017; Wu et al., 2017). For instance, Sharma et al. (2016) and Kuester et al. (2017) observed higher EMI SE values for hybrid composites containing CNT/GR and $\mathrm{CNT} / \mathrm{GnP}$, respectively, than those found for composites containing the individual fillers.
As previously mentioned, the selection of the polymer matrix is another important key to developing CPC for EMI shielding (Socher et al., 2011). Among insulating polymer matrices, thermoplastic polyurethane (TPU) is widely used due to its versatility. Besides its thermoplastic properties, TPU also has the elasticity of vulcanized rubbers without the need of the vulcanization process (Ramoa et al., 2013). In addition, TPU is composed of two-phase microstructure based on a soft polyester or polyether phase reinforced by a hard phase of aromatic diisocyanate extended with a short-chain diol. Moreover, several studies have reported the production of TPU/CNT composites using various manufacturing methods including solution and melt processing (Guo et al., 2008; Ramoa et al., 2013; Chen et al., 2015). Generally, CNT-filled polymer composites show a better EMI shielding effectiveness and electrical conductivity values at the same filler content when compared to the conductive carbon black (CB)-filled polymer composites. However, composites containing high amount of CNT are more expensive and difficult to process than CB-filled polymer composites. Based on this context, this work proposes the preparation of conductive hybrid composites composed of carbon black modified with polypyrrole (CB-PPy), CNT, and TPU matrix through melt mixing in order achieve the best relationship between electrical conductivity, EMI shielding effectiveness and processability. The microstructure, electrical conductivity, rheological properties and EMI SE of TPU/CB-PPy/CNT hybrid composites were evaluated and compared to those obtained for TPU/CB-PPy and TPU/CNT composites.

\section{EXPERIMENTAL}

\section{Materials}

The thermoplastic polyether-based polyurethane Elastollan ${ }^{\circledR}$ 1180 A10 used in this study was supplied by Basf -Brasil.

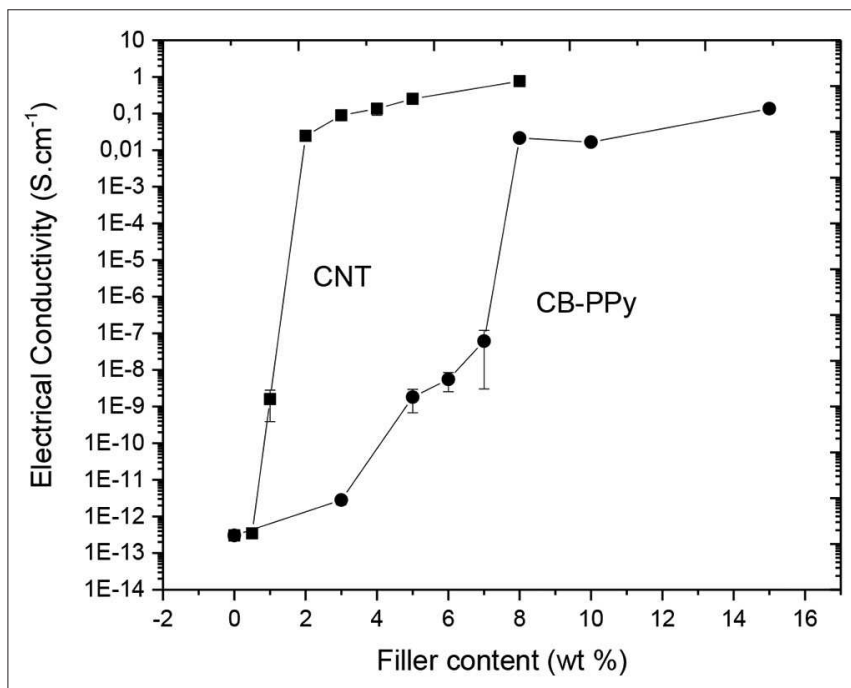

FIGURE 1 | Electrical conductivity of TPU/CNT and TPU/CB-PPy as function of filler content. 
It was characterized by a specific gravity of $1.11 \mathrm{~g} . \mathrm{cm}^{-3}$ and electrical conductivity of $10^{-13} \mathrm{~S} . \mathrm{cm}^{-1}$. The multi walled carbon nanotubes were provided by Nanocyl SA (NC 7000) with carbon purity of $90 \%$, average diameter of $9.5 \mathrm{~nm}$, average length of $1.5 \mu \mathrm{m}$ and electrical conductivity of $10^{4} \mathrm{~S}_{\mathrm{cm}} \mathrm{cm}^{-1}$. Carbon black/polypyrrole was purchased from Sigma Aldrich (80 wt\% of carbon black) with electrical conductivity $3 \times 10^{1}{\mathrm{~S} . \mathrm{cm}^{-1}}^{-1}$.

\section{Composites and Sample Preparation}

The composites were prepared by melt blending with different amounts of carbon black/polypyrrole (from 0 to $15 \mathrm{wt} \%$ ) and carbon nanotubes (from 0 to $8 \mathrm{wt} \%$ ). Initially, the materials were dried overnight at $60^{\circ} \mathrm{C}$. The hybrid composites were produced with 3,5 , and $8 \mathrm{wt} \%$ of total filler and the fraction of each filler was $25: 75,50: 50$, and 75:25. Then, the polymer and the fillers were mixed in a Thermo Haake Polylab Rheomix 600p internal mixer at a rotor speed of $60 \mathrm{rpm}$ for $15 \mathrm{~min}$ and at $170^{\circ} \mathrm{C}$. The mixed compounds were molded (in square plaques) by thermocompression using a hydraulic press at $170^{\circ} \mathrm{C}$ for $5 \mathrm{~min}$ and under a $15 \mathrm{MPa}$ pressure.

\section{Methodology}

The electrical conductivity of the high-conductive samples was measured using a four-probe standard method. The current source was a Keithley 6220 equipment and the voltage was measured by a Keithley electrometer Model 6517A. For the highresistive samples a two-probe standard method was performed by a Keithley 6517A electrometer connected to a Keithley 8009 test fixture. The sample thickness was $0.5 \mathrm{~mm}$ and the measures were performed on both sides of three different films.
A field emission gun scanning electron microscope (FEGSEM) Jeol model JSM-6701F was used to investigate the morphology and the filler dispersion. The samples were prepared using liquid nitrogen to break the films in a brittle manner and the fractured surface was sputtered with a gold layer. A tension of $10 \mathrm{kV}$ was applied during the analyses. Different regions of a sample were analyzed.

The rheological properties of the composites in the molten state were measured by a dynamic oscillatory rheometer ThermoHaake MARS II with $20 \mathrm{~mm}$ plate-plate geometry at $170^{\circ} \mathrm{C}$. The analysis was carried out under a nitrogen atmosphere and the frequency scanned from 0.01 to $100 \mathrm{~Hz}$. Three specimens were analyzed and the thickness and the diameter of the samples were $1 \mathrm{~mm}$ and $25 \mathrm{~mm}$, respectively.

The EMI SE analysis was performed by a N5230C Agilent Technology PNA series analyser in the X-band frequency range $(8.2-12.4 \mathrm{GHz})$ connected to a waveguide used as the sample holder. The thickness of the samples was $2 \mathrm{~mm}$ and three specimens of each composition were analyzed. The contribution of reflection $\left(\mathrm{SE}_{\mathrm{R}}\right)$ and absorption $\left(\mathrm{SE}_{\mathrm{A}}\right)$ shielding on the total EMI SE values was determined using the experimental power data (incident $(\mathrm{I})$, reflected $(\mathrm{R})$ and transmitted $(\mathrm{T})$ power) and equations (1)-(3):

$$
\begin{aligned}
S E_{R} & =10 \log \frac{\mathrm{I}}{\mathrm{I}-\mathrm{R}} \\
S E_{A} & =10 \log \frac{\mathrm{I}-\mathrm{R}}{\mathrm{T}} \\
\text { EMISE } & =10 \log \frac{\mathrm{I}}{\mathrm{T}}
\end{aligned}
$$

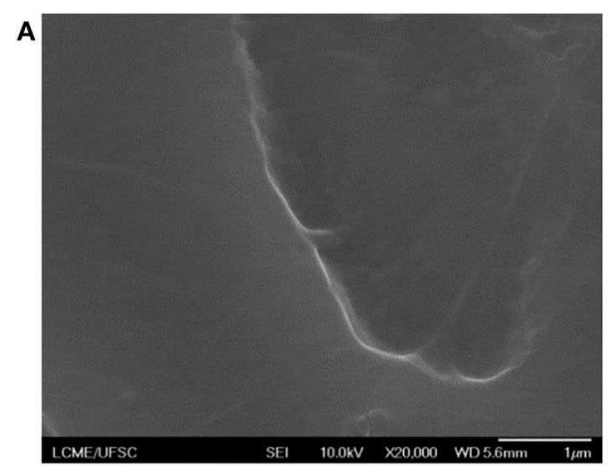

B

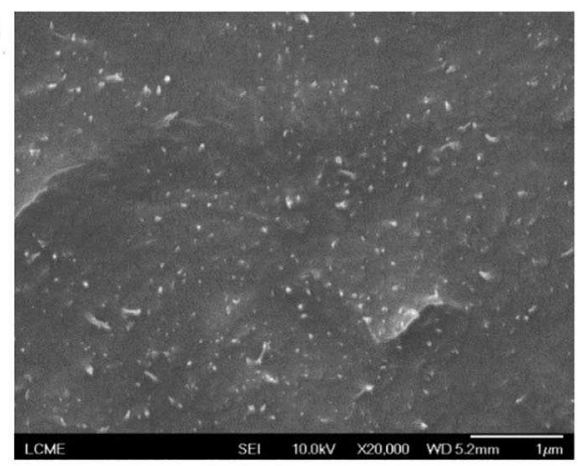

c 


\section{RESULTS AND DISCUSSION}

In order to evaluate the effect of CB-PPy and CNT contents on the electrical conductivity of the TPU matrix, composites based on TPU/CB-PPy and TPU/CNT were produced. As shown in Figure 1, TPU/CNT composites exhibit a very sharp insulator-conductor transition and the electrical conductivity enhances significantly with increasing CNT content. The electrical conductivity of TPU/CNT composites containing 1 and $2 \mathrm{wt} \%$ of filler increased $10^{4}$ and $10^{11}$ times, respectively, when compared to the neat TPU $\left(10^{-13} \mathrm{~S} . \mathrm{cm}^{-1}\right)$, reaching a maximum value of about $1 \mathrm{~S} . \mathrm{cm}^{-1}$ at $8 \mathrm{wt} \%$ of CNT content. These values are quite similar to those observed by Ramoa et al. (2013) and Zhang et al. (2007), suggesting that a good dispersion of CNT into TPU matrix was achieved. On the other hand, a slight increase on the electrical conductivity with the increasing in CB-PPy content was observed. This behavior can be assigned to the higher aspect ratio and better distribution of CNT into the TPU matrix
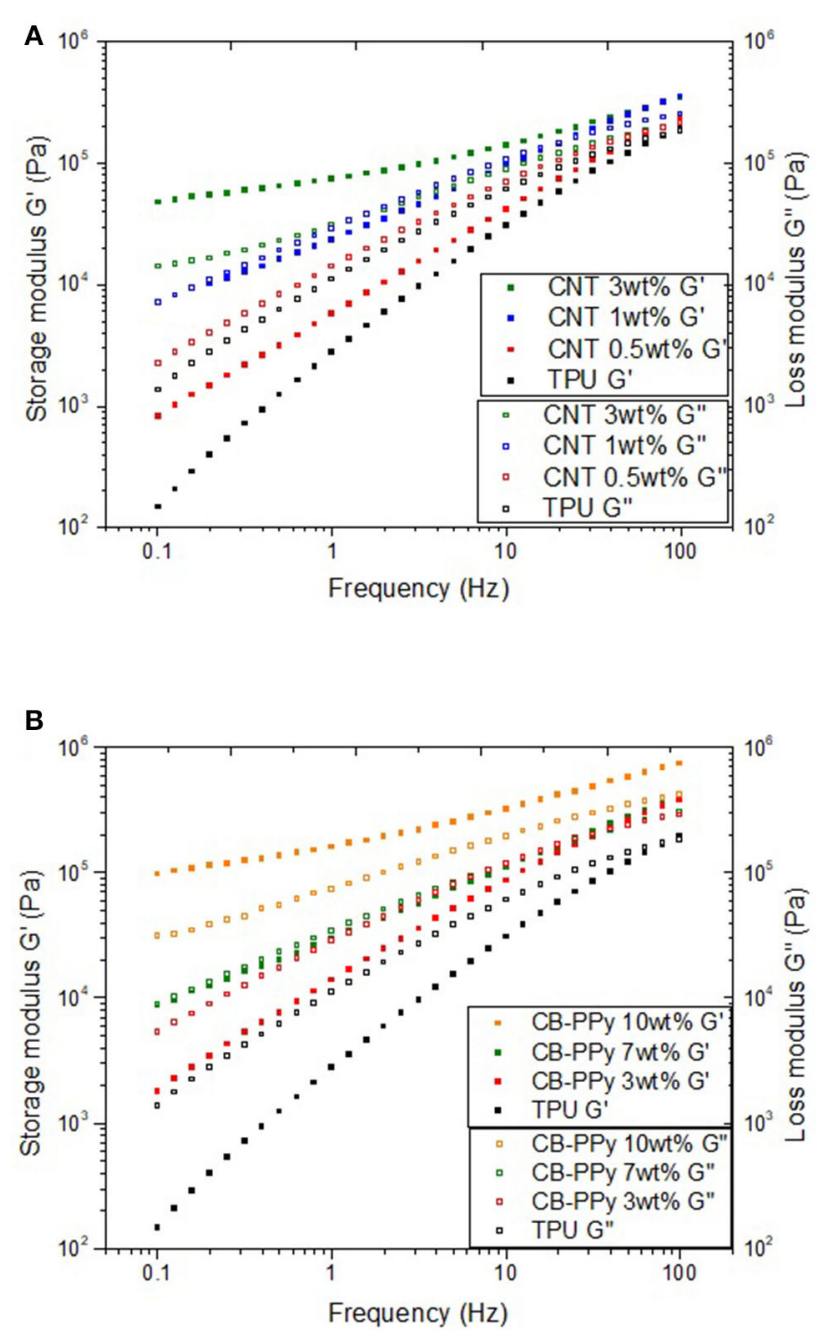

FIGURE 3 | Storage modulus as a function of conductive filler content and frequency for (A) TPU/CNT and (B) TPU/CB-PPy. than those found for CB-PPy. In fact, the percolation threshold $\left(f_{p}\right)$ and the critical exponent $(t)$ determined by a power law equation (Equation 4) for TPU/CNT were 1 wt\% and 2.4, respectively, while TPU/CB-PPy showed a higher percolation

TABLE 1 | Complex viscosity of TPU and composites composition.

\begin{tabular}{lcc}
\hline Material & $\begin{array}{c}\text { Composition } \\
\text { (wt\%) }\end{array}$ & $\begin{array}{r}\text { Complex visco } \\
\text { at } \mathbf{~} \mathbf{~ H z} \\
\mathbf{( P a . s})\end{array}$ \\
& & \\
TPU & 100 & 2.1 \\
TPU/CNT & $97 / 3.0$ & 82.4 \\
TPU/CB-PPy & $97 / 3.0$ & 8.4 \\
TPU/CNT & $95 / 5.0$ & 142.2 \\
TPU/CB-PPy & $95 / 5.0$ & 14.8 \\
TPU/CNT & $92 / 8.0$ & 358.9 \\
TPU/CB-PPy & $92 / 8.0$ & 34.1
\end{tabular}
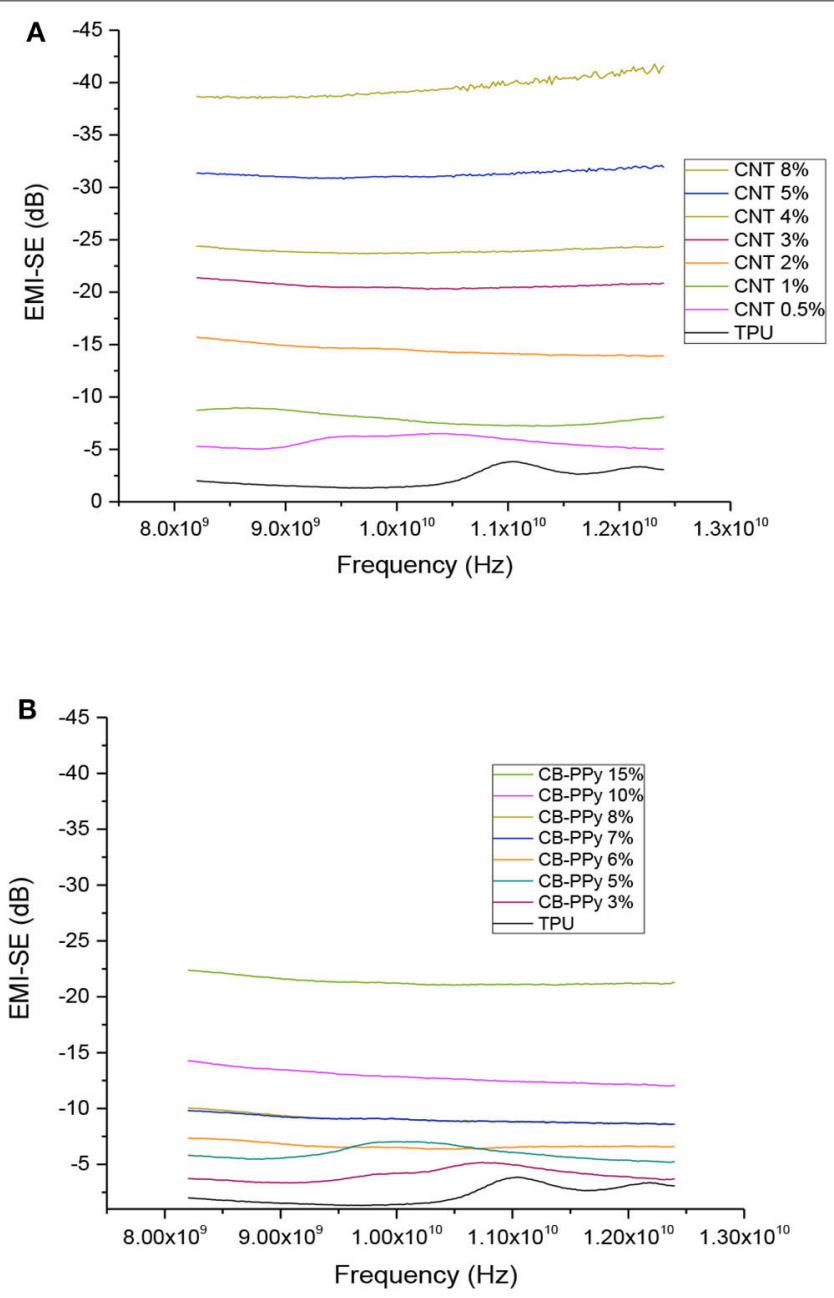

FIGURE 4 | EMI SE of (A) TPU/CNT and (B) TPU/CB-PPy composites with different amounts of CNT and CB-PPy. 
threshold, $7 \mathrm{wt} \%$, and lower t, 2.1. For both composites, the critical exponent was higher than 2, which implies multiple percolation or tunneling (Levon et al., 1993).

$$
\sigma=c\left(f-f_{p}\right)^{t}
$$

$\sigma$ is the electrical conductivity of the composites, $\mathrm{c}$ is a constant, $\mathrm{f}$ is the filler weight content, $\mathrm{f}_{\mathrm{p}}$ is the filler weight content at the percolation threshold and $\mathrm{t}$ is the critical exponent. The critical exponent $t$ is related to the number of contacts between the fillers at the percolation threshold. The Equation 4 is used as an empirical approximation for mixtures with weight fraction compositions.

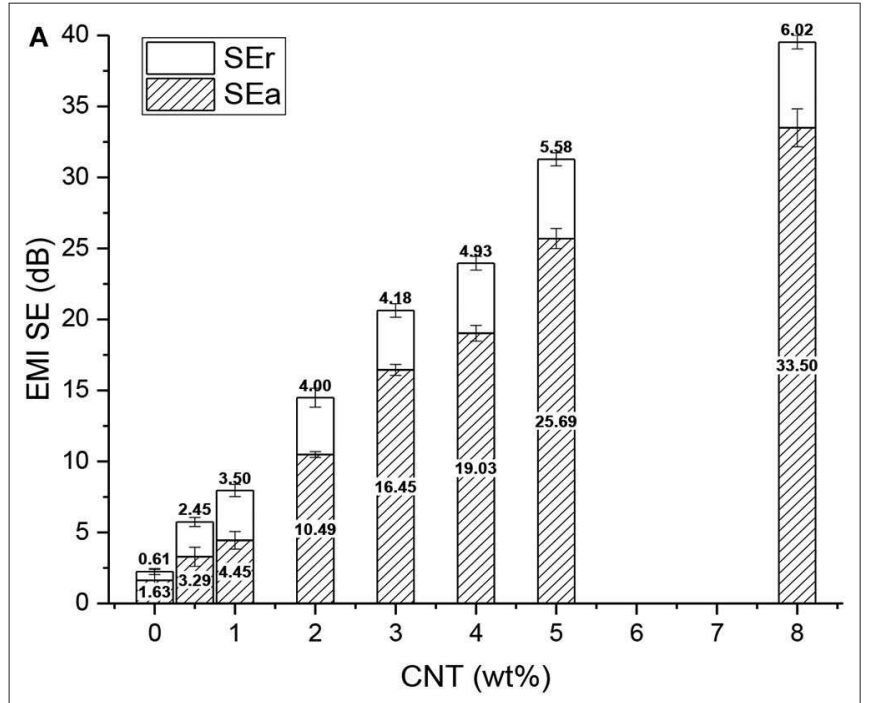

B

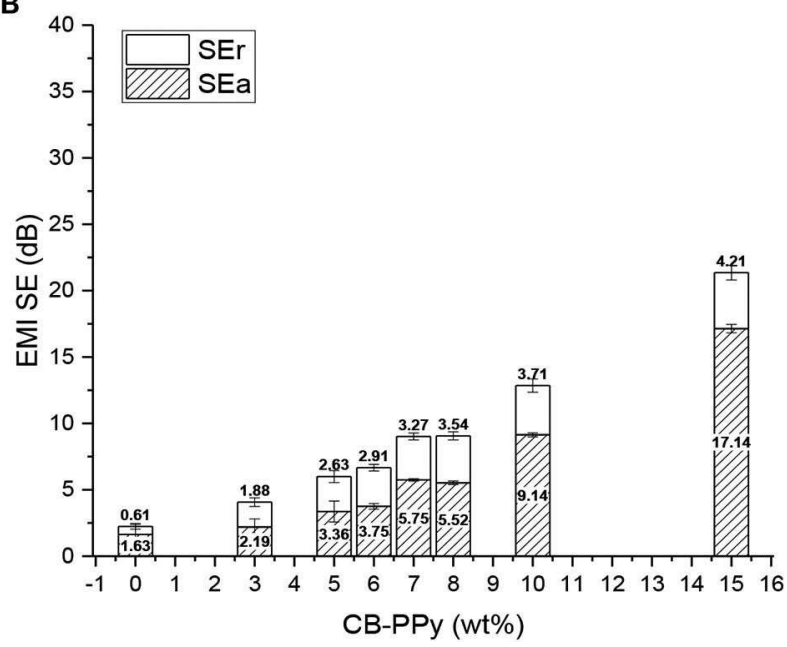

FIGURE 5 | Total EMI SE, $\mathrm{SE}_{\mathrm{A}}$ and $\mathrm{SE}_{\mathrm{R}}$ values of composites as a function (A) CNT and (B) CB-PPy content measured at $9 \mathrm{GHz}$.
FEG-SEM micrographs of cryogenically fractured surfaces of neat TPU, TPU/CNT, and TPU/CB-PPy composites containing $8 \mathrm{wt} \%$ of the conductive fillers are observed in Figure 2. The white points correspond to the disperse phase into TPU matrix. The microstructure of both composites shows a typical separation and the presence of conductive filler agglomerates well-dispersed contributing to the formation of a conducive pathway in the TPU matrix. As discussed on the above, CNT have high aspect ratio, therefore, small filler content is necessary to create a conductive network in the TPU matrix reducing the percolation threshold. On the other hand, carbon blackpolypyrrole has spherical morphology with low aspect ratio and higher percolation threshold, which means a larger amount of this filler is necessary to form a conductive path.

The storage modulus $\left(G^{\prime}\right)$ and loss modulus $\left(G^{\prime \prime}\right)$ as a function of the conductive filler and the frequency for both TPU/CNT and TPU/CB-PPy composites are shown in Figure 3. The neat TPU presents a liquid-like behavior $\left(G^{\prime \prime}>G^{\prime}\right)$ and its transition from liquid to solid-like behavior $\left(G^{\prime \prime}<G^{\prime}\right)$ is observed at a frequency of $64.8 \mathrm{~Hz}$. For both composites, $\mathrm{G}^{\prime}$ and $\mathrm{G}^{\prime \prime}$ increase significantly with the increasing in the conductive filler content into the TPU matrix, indicating that these systems exhibit a pseudo-solid-like behavior. TPU/CNT and TPU/CB-PPy composites with 0.5 and $3 \mathrm{wt} \%$ of filler content, respectively, exhibit a transition from liquid to solid-like behavior at the same frequency value found for the neat TPU, while the values for $G^{\prime}$ and $G^{\prime \prime}$ become almost independent of the frequency at lower frequencies for composites containing $3 \mathrm{wt} \%$ of CNT and $10 \mathrm{wt} \%$ of CB-PPy. The origin of this behavior can be assigned to the formation of a percolate network, in which the number of interfaces between conductive fillers into the insulating polymer matrix is considered.

It is important to highlight that complex viscosity of TPU (2.1 Pa.s) increases abruptly with increasing the CNT content, as shown in Table 1. For example, the complex viscosity of

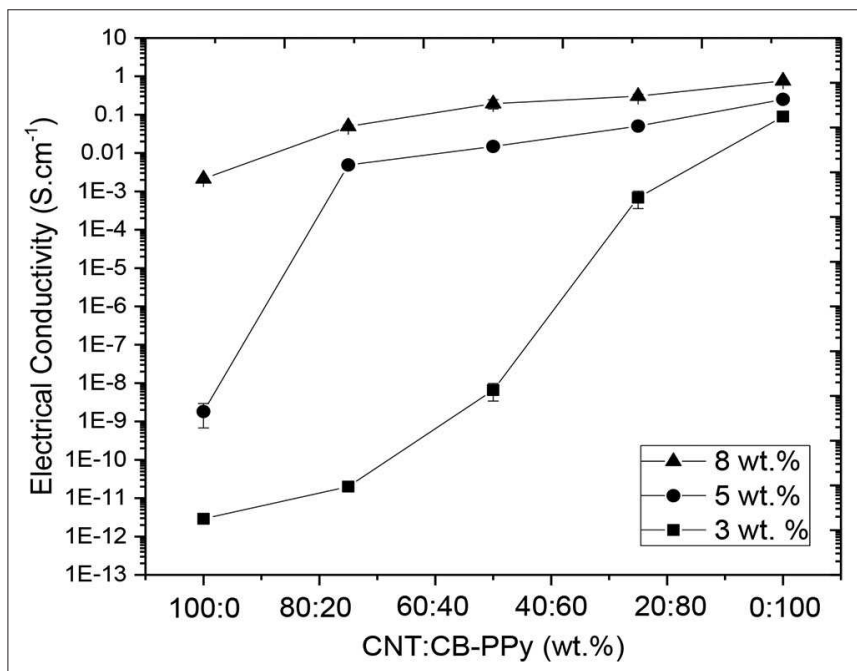

FIGURE 6 | Electrical conductivity of composites as a function of CNT/CB-PPy (wt\%) ratio for hybrid composites containing a total filler amount of 3,5 , and $8 w t \%$. 
neat TPU increased approximately 171 - and 16 -fold by adding 8 wt\% of CNT and CB-PPy, respectively. Moreover, TPU/CNT composites was partially impaired for CNT filler concentration above 8 wt $\%$. Therefore, conductive hybrid composites were produced to achieve the best relationship between electrical conductivity, EMI shielding effectiveness and processability at the same reducing the cost.

Figure 4 displays the effect of the conductive filler type and content on the EMI SE as a function of the frequency in the range of 8-12 GHz. TPU/CNT composites exhibit higher EMI $\mathrm{SE}$ at the same filler content in the whole frequency range when compared with TPU/CB-PPy due to the higher aspect ratio of $\mathrm{CNT}$, what leads to the easier creation of the filler path and consequently, higher increase in the electrical conductivity. For example, composites with $3 \mathrm{wt} \%$ of CNT and CB-PPy show EMI SE values of -21.2 and $-3.1 \mathrm{~dB}$, respectively. These results are in good agreement with the electrical conductivity, rheological properties and microstructure analyses of TPU/CNT and TPU/CB-PPy composites, as discussed previously. The EMI SE values of TPU/CNT composites obtained in the present work are higher than those reported by Liu et al. (2007) and Ramoa et al. (2013).

In addition, the EMI SE of TPU/CB-PPy is quite similar to that presented by Ramoa et al. (2013) for TPU/CB composites. Furthermore, the EMI SE values found for TPU/CNT composites containing 3 to $8 \mathrm{wt} \%$ of filler are similar or quite higher than those results observed in composites containing different carbonaceous fillers (Al-Saleh et al., 2013; Jeddi and Katbab, 2017; Kumar et al., 2017; Kuester et al., 2018). According to the literature ( $\mathrm{Li}$ et al., 2006), the desirable EMI SE is at least-20 $\mathrm{dB}$ for commercial application, which corresponds to $99 \%$ of radiation attenuation (Chen Z. et al., 2013; Ramoa et al., 2013). This value was reached for TPU composites containing $15 \mathrm{wt} \%$ of CB-PPy and $3 \mathrm{wt} \%$ of CNT.

Figure 5 illustrates the relationship between the conductive filler and the contribution on the EMI SE by reflection and

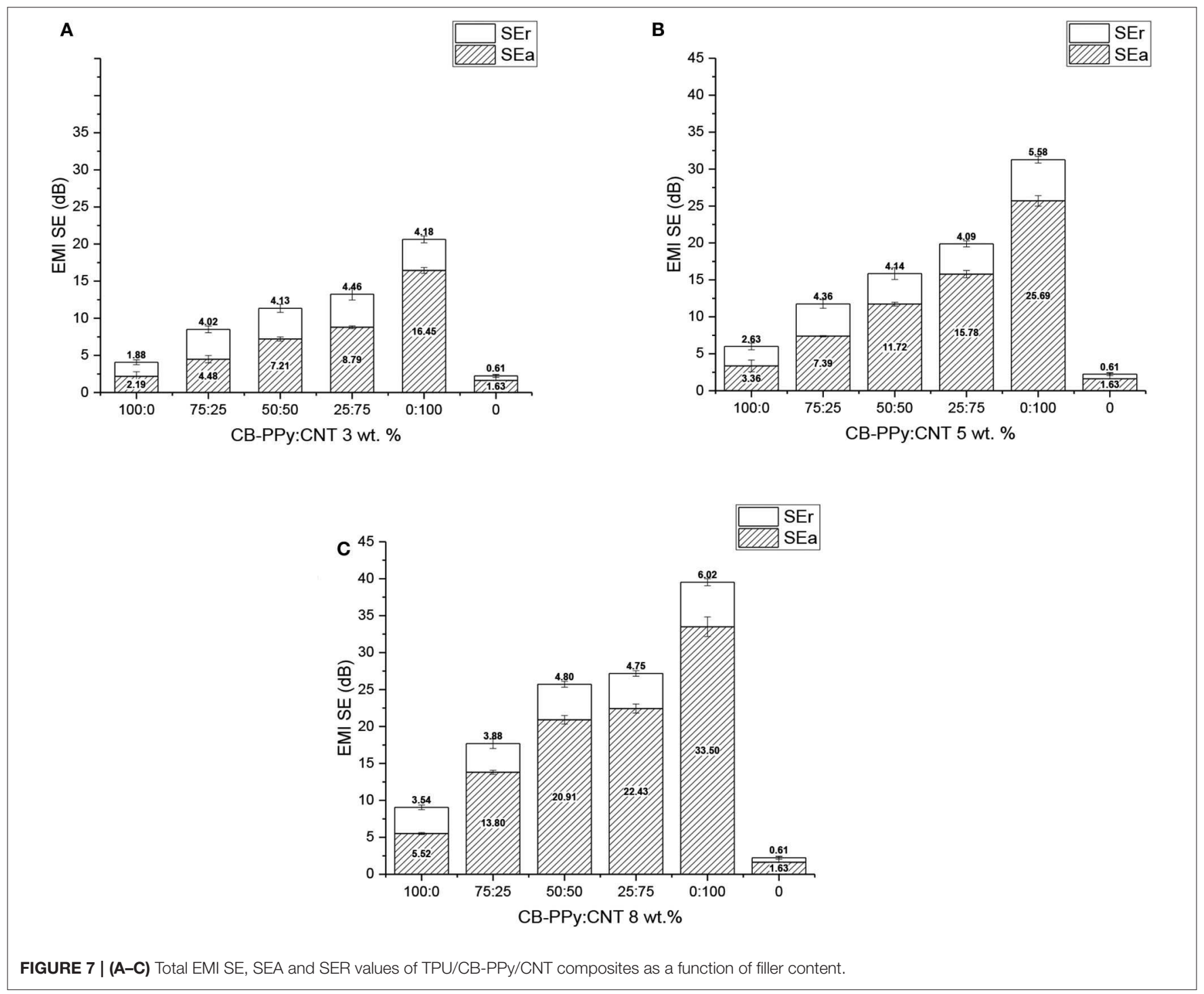


TABLE 2 | Values of $\mathrm{SE}_{\mathrm{A}}, \mathrm{SE}_{\mathrm{R}}$ and electrical conductivity for hybrids composites of TPU/CNT/CB-PPy measured at $10 \mathrm{GHz}$.

\begin{tabular}{|c|c|c|c|c|c|c|c|c|}
\hline \multirow[t]{2}{*}{ CB-PPy/CNT } & \multicolumn{4}{|c|}{5 wt $\%$} & \multicolumn{4}{|c|}{$8 w t \%$} \\
\hline & $\mathrm{SE}_{\mathrm{R}}$ & $\mathrm{SE}_{A}$ & $\mathrm{SE}_{\mathrm{T}}$ & $\sigma$ & $S E_{R}$ & $\mathrm{SE}_{\mathrm{A}}$ & $\mathrm{SE}_{\mathrm{T}}$ & $\sigma$ \\
\hline $100 / 0$ & 2.63 & 3.36 & 5.99 & 1.82E-09 & 3.54 & 5.52 & 9.06 & $2.13 \mathrm{E}-03$ \\
\hline $75 / 25$ & 4.36 & 7.39 & 11.75 & 4.87E-03 & 3.88 & 13.80 & 17.68 & 4.96E-02 \\
\hline $50 / 50$ & 4.14 & 11.72 & 15.86 & 1.48E-02 & 4.80 & 20.91 & 25.71 & 1.94E-01 \\
\hline $25 / 75$ & 4.09 & 15.78 & 19.87 & 5.05E-02 & 4.75 & 22.43 & 27.18 & 3.05E-01 \\
\hline $0 / 100$ & 5.58 & 25.69 & 31.27 & $2.51 \mathrm{E}-01$ & 6.02 & 33.50 & 39.52 & 7.64E-01 \\
\hline
\end{tabular}

absorption shielding. The $\mathrm{SE}_{\mathrm{R}}$ and $\mathrm{SE}_{\mathrm{A}}$ increase with the increasing in the conductive filler content for both composites. Moreover, the $\mathrm{SE}_{\mathrm{A}}$ values for TPU/CNT at all compositions are higher than those found for TPU/CB-PPy composites, probably due to the higher aspect ratio, better distribution and better interaction between $\mathrm{CNT}$ and the electromagnetic radiation when compared to those observed for CB-PPy.

In order to reach a maximum EMI SE and electrical conductivity values at the lowest CB-PPy content, hybrid composites of TPU/CB-PPy/CNT were produced. The correlation between electrical conductivity and conductive filler fraction for (a) $3 \mathrm{wt} \%$, (b) $5 \mathrm{wt} \%$, and (c) $8 \mathrm{wt} \%$ of total filler content (CB-PPy/CNT) is illustrated in Figure 6. For composites with $3 \mathrm{wt} \%$ of total filler concentration having different filler ratios of $\mathrm{CNT} / \mathrm{CB}-\mathrm{PPy}=0 ; 0.25 ; 0.5 ; 0.75$; and 1 , the electrical conductivity increases with decreasing $\mathrm{CB}-\mathrm{PPy}$ content, indicating that CNT played an important role on the conductive network formation. On the other hand, the electrical conductivity for all hybrid composites containing 5 and 8 wt $\%$ of different filler ratio is quite similar probably due to the high amount of CNT concentration, which is higher than the percolation threshold for TPU/CNT composites.

Figure 7 illustrates the EMI SE of TPU/CB-PPy/CNT as a function of filler content. With increasing CNT content for the hybrid composites, the total EMI SE enhances and the main shielding mechanism is by absorption. For hybrid polymer composites containing $3 \mathrm{wt} \%$ of conductive filler, the EMI SE is lower than the desirable value for shielding material applications. As shown in Table 2, the EMI SE values are dependent on the electrical conductivity of the composites because of the conductive network formation. Therefore, polymer composites with electrical conductivity below $10^{-3} \mathrm{~S} . \mathrm{cm}^{-1}$ generally show EMI SE values lower than $-20 \mathrm{~dB}$. On the other hand, hybrid composites containing $5 \mathrm{wt} \%$ at CB-PPy/CNT ratio of 75:25 and $8 \mathrm{wt} \%$ at filler ratio of 75:25, 50:50, and 25:75 presented total EMI SE values higher than $-20 \mathrm{~dB}$, suggesting that those composites have a great potential as EMI shielding material.

\section{CONCLUSION}

Conducting polymer composites comprised of TPU/CB-PPy, TPU/CNT, and TPU/CB-PPy/CNT were successfully produced through melting mixing process. Electrical conductivity, rheological properties and EMI SE were significantly affected by the conductive network formation. Therefore, the increase of filler content resulted in the raise of the electrical conductivity and EMI SE values of both TPU composites. The electrical conductivity of composites with $3 \mathrm{wt} \%$ of CNT and $15 \mathrm{wt} \%$ of CB-PPy increases about 12 orders of magnitude when compared to that found for neat TPU. TPU/CNT exhibited the desired level of EMI SE, $-20 \mathrm{~dB}$, at a filler content higher than $3 \mathrm{wt} \%$ while 15 $\mathrm{wt} \%$ of CB-PPy is required to reach this value. This behavior can be assigned to the higher aspect ratio and better distribution of CNT filler into TPU matrix when compared to the CB-PPy filler. On the other hand, TPU composites containing CNT are more difficult to be processed at the same conductive filler content than CB-PPy-filled TPU composites. TPU/CNT composites was partially impaired for CNT filler concentration above $8 \mathrm{wt} \%$. Concerning the hybrid composites (TPU/CB-PPy/CNT), the CNT play an important role on the electrical conductivity, EMI and rheological properties. In fact, with increasing the CNT content in the TPU/CB-PPy/CNT these properties enhance significantly. A schematic drawing of the interaction between CNT/CB-PPy particles is shown in the Supplementary Figure. For hybrid polymer composites containing $3 \mathrm{wt} \%$ of conductive filler, the EMI SE is lower than the desirable value for shielding material applications. Moreover, hybrid composites with good processability at $5 \mathrm{wt} \%$ of CNT/CB-PPy ratio 75:25 and $8 \mathrm{wt} \%$ of filler ratio 75:25, 50:50, and 25:75 presented total EMI SE values higher than $-20 \mathrm{~dB}$, demonstrating the potential use of these materials for electromagnetic shielding applications.

\section{DATA AVAILABILITY STATEMENT}

All datasets generated for this study are included in the article/Supplementary Material.

\section{AUTHOR CONTRIBUTIONS}

$\mathrm{MB}$ and SR performed the production of polymer composites composition and characterization. CM, GB, BS, and AP assisted in writing of the manuscript and discussion of results. All authors reviewed the final manuscript.

\section{ACKNOWLEDGMENTS}

The authors gratefully acknowledge the financial support of the Conselho Nacional de Desenvolvimento Científico e Tecnológico (CNPq), the Coordenação de Aperfeiçoamento de Pessoal de Ensino Superior (CAPES), the Fundação de Amparo à Pesquisa E Inovação do Estado de Santa Catarina (FAPESC), and the Central Electron Microscopy Laboratory of the Universidade Federal de Santa Catarina (LCME-UFSC) for the FEG-SEM images.

\section{SUPPLEMENTARY MATERIAL}

The Supplementary Material for this article can be found online at: https://www.frontiersin.org/articles/10.3389/fmats. 2020.00174/full\#supplementary-material 


\section{REFERENCES}

Al-Saleh, M. H. (2015). Electrical and mechanical properties of graphene/carbon nanotube hybrid nanocomposites. Synth. Met. 209, 41-46. doi: 10.1016/j.synthmet.2015.06.023

Al-Saleh, M. H. (2016). Electrical, EMI shielding and tensile properties of PP/PE blends filled with GNP:CNT hybrid nanofiller. Synth. Met. 217, 322-330. doi: 10.1016/j.synthmet.2016.04.023

Al-Saleh, M. H., Saadeh, W. H., and Sundararaj, U. (2013). EMI shielding effectiveness of carbon based nanostructured polymeric materials: a comparative study. Carbon 60, 146-156. doi: 10.1016/j.carbon.2013.04.008

Burmistrov, I., Gorshkov, N., Ilinykh, I., Muratov, D., Kolesnikov, E., Anshin, S., et al. (2016). Improvement of carbon black based polymer composite electrical conductivity with additions of MWCNT. Compos. Sci. Technol. 129, 79-85. doi: 10.1016/j.compscitech.2016.03.032

Chen, J., Du, X. C., Zhang, W. B., Yang, J. H., Zhang, N., Huang, T., et al. (2013). Synergistic effect of carbon nanotubes and carbon black on electrical conductivity of PA6/ABS blend. Compos Sci Technol. 81, 1-8. doi: 10.1016/j.compscitech.2013.03.014

Chen, J., Zhang, Z. X., Huang, W. B., Li, J. L., Yang, J. H., Wang, Y., et al. (2015). Carbon nanotube network structure induced strain sensitivity and shape memory behavior changes of thermoplastic polyurethane. Mater. Design 69, 105-113. doi: 10.1016/j.matdes.2014.12.054

Chen, Z., Xu, C., Ma, C., Ren, W., and Cheng, H. M. (2013). Lightweight and flexible graphene foam composites for high-performance electromagnetic interference shielding. Adv. Mater. 25, 1296-1300. doi: 10.1002/adma.201204196

Chu, K., Li, W. S., Jia, C. C., and Tang, F. L. (2012). Thermal conductivity of composites with hybrid carbon nanotubes and graphene nanoplatelets. Appl. Phys. Lett. 101, 211903-2119034. doi: 10.1063/1.4767899

Guo, S., Zhang, C., Wang, W., Liu, T., Tjiu, W. C., He, C., et al. (2008). Preparation and characterization of polyurethane/multiwalled carbon nanotube composites. Polym. Polym. Comp. 16, 501-507. doi: 10.1177/096739110801600803

Håkansson, E., Amiet, A., Nahavandi, S., and Kaynak, A. (2007). Electromagnetic interference shielding and radiation absorption in thin polypyrrole films. Eur. Polymer J. 43, 205-213. doi: 10.1016/j.eurpolymj.2006.10.001

Jang, M. G., Cho, C., and Kim, W. N. (2016). Synergistic effects of hybrid conductive fillers on the electrical properties of carbon fiber pultruded polypropylene/polycarbonate composites prepared by injection molding. J. Comp. Mater. 51, 1005-1017. doi: 10.1177/0021998316658536

Jeddi, J., and Katbab, A. A. (2017). The electrical conductivity and EMI shielding properties of polyurethane foam/silicone rubber/carbon black/nanographite hybrid composites. Polym. Comp. 39, 3452-3460. doi: 10.1002/pc.24363

Kaur, A., Ishpal, D., and Hawan, S. K. (2012). Tuning of EMI shielding properties of polypyrrole nanoparticles with surfactant concentration. Synth. Metals 162, 1471-1477. doi: 10.1016/j.synthmet.2012.05.012

Kausar, A. (2016). Electromagnetic interference shielding of polyaniline/poloxalene/carbon black composite. Int. J. Mater. Chem. 6, 6-11. doi: 10.5923/j.ijmc.20160601.02

Kim, B. R., Lee, H. K., Park, S. H., and Kim, H. K. (2011). Electromagnetic interference shielding characteristics and shielding effectiveness of polyanilinecoated films. Thin Solid Films 19, 3492-3496. doi: 10.1016/j.tsf.2011.01.093

Kuester, S., Barra, G. M. O., and Demarquette, N. R. (2018). Morphology, mechanical properties and electromagnetic shielding effectiveness of poly (styrene-b-ethylene-ran-butylene-b-styrene)/carbon nanotube nanocomposites: effects of maleic anhydride, carbon nanotube loading and processing method. Polymer Int. 67, 1229-1240. doi: 10.1002/pi.5630

Kuester, S., Demarquette, N. R., Ferreira, J. C., Soares, B. G., and Barra, G. M. O. (2017). Hybrid nanocomposites of thermoplastic elastomer and carbon nanoadditives for electromagnetic shielding. Eur. Polym. J. 88, 328-339. doi: 10.1016/j.eurpolymj.2017.01.023

Kuester, S., Merlini, C., Barra, G. M. O., Ferreira, J. C., Lucas, A., de Souza, A. C., et al. (2016). Processing and characterization of conductive composites based on poly(styrene-b-ethylene-ran-butylene-b-styrene) (SEBS) and carbon additives: a comparative study of expanded graphite and carbon black. Comp. Part B Eng. 84, 236-247. doi: 10.1016/j.compositesb.2015.09.001
Kumar, A., Kumar, V., Kumar, M., and Awasthi, K. (2017). Synthesis and characterization of hybrid PANI/MWCNT nanocomposites for EMI applications. Polym. Comp. 39, 3858-3868. doi: 10.1002/pc.24418

Kumar, G. S., and Patro, T. U. (2018). Efficient electromagnetic interference shielding and radar absorbing properties of ultrathin and flexible polymer-carbon nanotube composite films. Mater. Res. Exp. 5:115304. doi: 10.1088/2053-1591/aade39

Levon, K., Margolina, A., and Patashinsky, A. Z. (1993). Multiple percolation in conducting polymer blends. Macromolecules 26, 4061-4063. doi: 10.1021/ma00067a054

Li, N., Huang, Y., Du, F., He, X., Lin, X., Gao, H., et al. (2006). Electromagnetic interference (EMI) shielding of single-walled carbon nanotube epoxy composites. Nano Lett. 6, 1141-1145. doi: 10.1021/nl0602589

Liu, Z., Bai, G., Huang, Y., Ma, Y., Du, F., Li, F., et al. (2007). Reflection and absorption contributions to the electromagnetic interference shielding of single-walled carbon nanotube/polyurethane composites. Carbon 45, 821-827. doi: 10.1016/j.carbon.2006.11.020

Mahapatra, S. P., Sridhar, V., and Tripathy, D. K. (2008). Impedance analysis and electromagnetic interference shielding effectiveness of conductive carbon black reinforced microcellular EPDM rubber vulcanizates. Polym. Comp. 29, 465-472. doi: 10.1002/pc.20421

Mondal, S., Das, P., Ganguly, S., Ravindren, R., Remanan, S., Bhawal, P., et al. (2018). Thermal-air ageing treatment on mechanical, electrical, and electromagnetic interference shielding properties of lightweight carbon nanotube based polymer nanocomposites. Compos. Part A. 107, 447-460. doi: 10.1016/j.compositesa.2018.01.025

Oyharçabal, M., Olinga, T., Foulc, M. P., Lacomme, S., Gontier, E., and Vigneras, V. (2013). Influence of the morphology of polyaniline on the microwave absorption properties of epoxy polyaniline composites. Compos. Sci. Technol. 74, 107-112. doi: 10.1016/j.compscitech.2012.10.016

Pan, Y., Liu, X., Hao, X., Star,ý, Z., and Schubert, D. W. (2016). Enhancing the electrical conductivity of carbon black-filled immiscible polymer blends by tuning the morphology. Eur. Polym. J. 78:106-115. doi: 10.1016/j.eurpolymj.2016.03.019

Piana, F., and Pionteck, J. (2013). Effect of the melt processing conditions on the conductive paths formation in thermoplastic polyurethane/expanded graphite (TPU/EG) composites. Comp. Sci. Technol. 80, 39-46. doi: 10.1016/j.compscitech.2013.03.002

Ramoa, S. D. A. S., Barra, G. M. O., Oliveira, R. V. B., de Oliveira, M. G., Cossad, M., and Soares, B. G. (2013). Electrical, rheological and electromagnetic interference shielding properties of thermoplastic polyurethane/carbon nanotube composites. Polym. Int. 62, 1477-1484. doi: 10.1002/pi.4446

Sharma, S. K., Gupta, V., Tandon, R. P., and Sachdev, V. K. (2016). Synergic effect of graphene and MWCNT fillers on electromagnetic shielding properties of graphene-MWCNT/ABS nanocomposites. RSC Adv. 6, 18257-18265. doi: 10.1039/C5RA23418B

Socher, R., Krause, B., Boldt, R., Hermasch, S., Wursche, R., and Pötschke, P. (2011). Melt mixed nano composites of PA12 with MWNTs: influence of MWNT and matrix properties on macrodispersion and electrical properties. Compos. Sci. Technol. 71, 306-314. doi: 10.1016/j.compscitech.2010.11.015

Sudha, J. D., Sivakala, S., Prasanth, R., Reena, V. L., and Nair, P. R. (2009). Development of electromagnetic shielding materials from the conductive blends of polyaniline and polyaniline-clay nanocompositeEVA: preparation and properties. Comp. Sci. Technol. 69, 358-364. doi: 10.1016/j.compscitech.2008.10.026

Sumfleth, J., Adroher, X. C., and Schulte, K. (2009). Synergistic effects in network formation and electrical properties of hybrid epoxy nanocomposites containing multi-wall carbon nanotubes and carbon black. J. Mater. Sci. 44, 3241-3247. doi: 10.1007/s10853-009-3434-7

Szeluga, U., Kumanek, B., and Trzebicka, B. (2015). Synergy in hybrid polymer/nanocarbon composites: a review. Compos. Part A. Appl. Sci. Manuf. 73, 204-231. doi: 10.1016/j.compositesa.2015.02.021

Taunk, M., Kapil, A., and Chand, S. (2008). Synthesis and electrical characterization of self-supported conducting polypyrrolePoly(vinylidene fluoride) composite films. Open Macromol. J. 2, 74-79. doi: 10.2174/1874343900802010074 
Wu, J., Ye, Z., Ge, H., Chen, J., Liu, W., and Liu, Z. (2017). Modified carbon fiber/magnetic graphene/epoxy composites with synergistic effect for electromagnetic interference shielding over broad frequency band. J. Colloid Interf. Sci. 506, 217-226. doi: 10.1016/j.jcis.2017. 07.020

Yavuz, Ö., Ram, M. K., Aldissi, M., Poddar, P., and Srikanth, H. (2005). Polypyrrole composites for shielding applications. Synth. Metals 151, 211-217. doi: 10.1016/j.synthmet.2005.05.011

Yu, W. C., Wang, T., Zhang, G. Q., Wang, Z. G., Yin, H. M., Yan, D. X., et al. (2018). Largely enhanced mechanical property of segregated carbon nanotube/poly(vinylidene fluoride) composites with high electromagnetic interference shielding performance. Compos. Sci. Technol. 167:260-267. doi: 10.1016/j.compscitech.2018.08.013

Zhang, C. S., Fu, S. Y., Ni, Q. Q., and Kurashiki, K. (2007). Electromagnetic interference shielding effect of nanocomposites with carbon nanotube and shape memory polymer. Compos. Sci. Technol. 67, 2973-2980. doi: 10.1016/j.compscitech.2007.05.011

Zhang, H., Zhang, G., Tang, M., Zhou, L., Li, J., Fan, X., et al. (2018). Synergistic effect of carbon nanotube and graphene nanoplates on the mechanical, electrical and electromagnetic interference shielding properties of polymer composites and polymer composite foams. Chem. Eng. J. 353, 381-393. doi: 10.1016/j.cej.2018.07.144

Zhang, S. M., Lin, L., Deng, H., Gao, X., Bilotti, E., Peijs, A. A. J. M., et al. (2012). Synergistic effect in conductive networks constructed with carbon nanofillers in different dimensions. Exp. Polym. Lett. 6, 159-168. doi: 10.3144/expresspolymlett.2012.17

Conflict of Interest: The authors declare that the research was conducted in the absence of any commercial or financial relationships that could be construed as a potential conflict of interest.

Copyright () 2020 Bertolini, Ramoa, Merlini, Barra, Soares and Pegoretti. This is an open-access article distributed under the terms of the Creative Commons Attribution License (CC BY). The use, distribution or reproduction in other forums is permitted, provided the original author(s) and the copyright owner(s) are credited and that the original publication in this journal is cited, in accordance with accepted academic practice. No use, distribution or reproduction is permitted which does not comply with these terms. 